\title{
Elsevier Science on the Internet
}

Your comprehensive and easy-to-use guide to the world-wide range of Elsevier Science products and services.

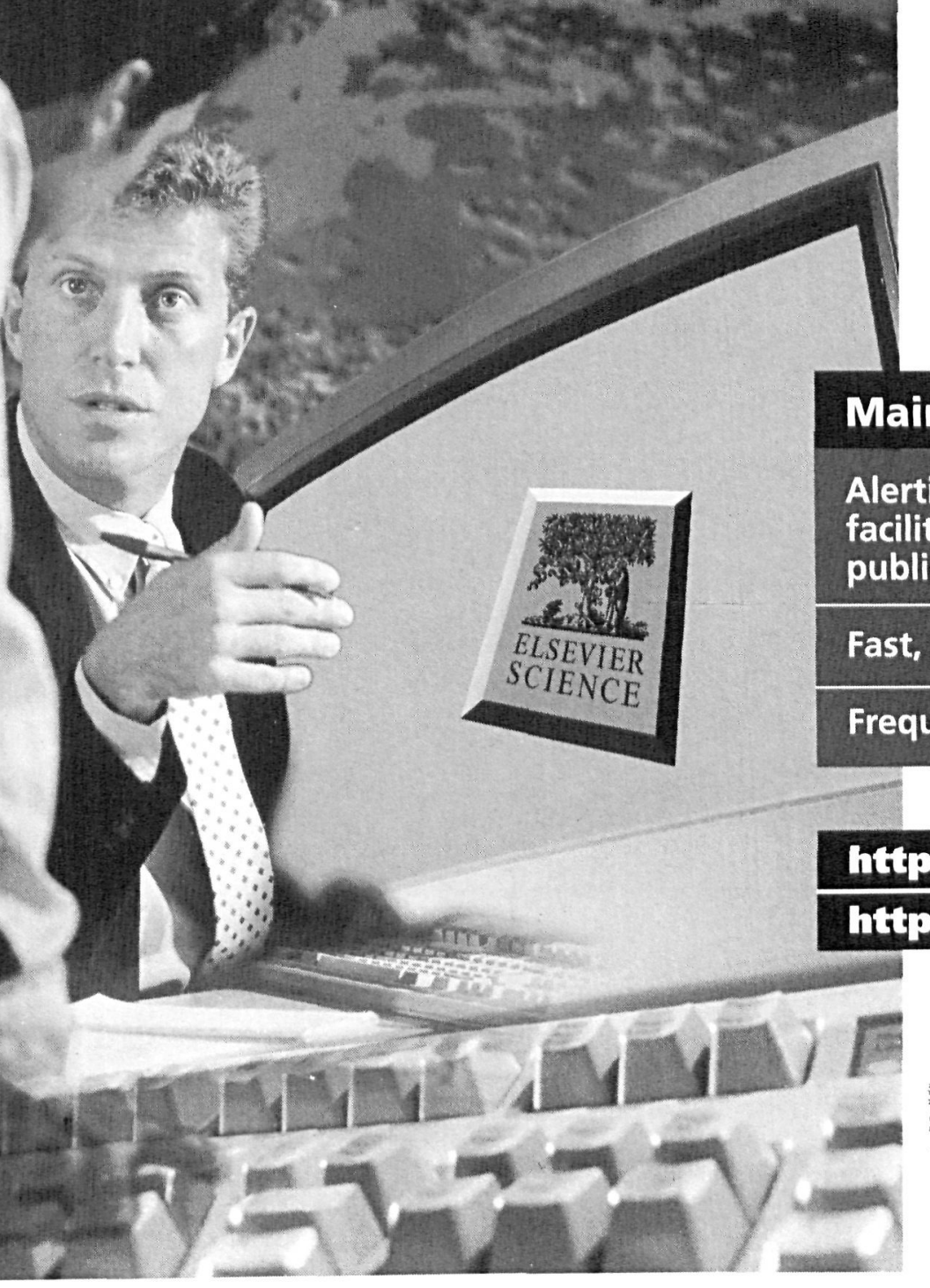

Visit Elsevier Science

on the Internet and access

a unique repository of

information covering the

entire scientific spectrum.

Our time-saving search

facilities will lead you

to our frequent updates

in seconds.

\section{Main features include:}

Alerting and awareness facilities for new and forthcoming publications.

Fast, time-saving search facilities.

Fequent updates.

\section{http://unu,elsevier.com}

ttpa/hum elseviernl 
